\title{
Clinical Role of Swept Source Anterior Segment Optical Coherence Tomography in Strabismus Re-Operation with Lost Surgical Details
}

\author{
Amar Pujari (D) \\ Sujeeth Modaboyina \\ Deepsekhar Das (ID \\ Asmita Mahajan \\ Rajeswari Thangavel \\ Swati Phuljhele \\ Rohit Saxena (D) \\ Namrata Sharma (D) \\ Pradeep Sharma
}

Dr. Rajendra Prasad Centre for Ophthalmic Sciences, All India Institute of Medical Sciences, New Delhi, India
Correspondence: Amar Pujari

Dr. Rajendra Prasad Centre for

Ophthalmic Sciences, All India Institute of

Medical Sciences, Room No. 212, RPC-I,

AlIMS, New Delhi, India

Tel +9l 8447226221

Email dramarpujari@gmail.com
Background: To characterize the diagnostic role of swept source anterior segment optical coherence tomography (SS-ASOCT) in strabismus re-operations with lost surgical details.

Methods: Patients presenting to our outpatient services for strabismus care from February 2020 to March 15th 2021 were systematically evaluated. Those willing to undergo re-operation were included in the study. A total of 30 patients were identified and out of this a total of 10 eyes of 10 patients with lost surgical details were finally included in the study. Demographic details, preoperative deviation, ocular findings, orthoptic measurements, detailed SS-ASOCT findings, intraoperative measurements, and post-operative outcomes were recorded.

Results: The mean age of 10 patients was $23.7 \pm 5.75$ years. Seven were male and three were female. The mean pre-operative SS-ASOCT measured distance from angle to insertion was $8.90 \pm 1.85 \mathrm{~mm}$ and the mean intraoperative distance was $9.12 \pm 2.14 \mathrm{~mm}$. A mean difference of $0.21 \pm 1.31 \mathrm{~mm}$ was noted, and this difference was statistically insignificant (paired $t$ test, $\mathrm{p}=0.57)$. In addition, SS-ASOCT unraveled novel signs to differentiate operated eyes from the un-operated eyes, and recessed muscle from the resected muscle.

Conclusion: In strabismus re-operation with lost surgical details, the pre-operative SSASOCT can provide reliable muscle details with respect to its type of surgery and amount surgery.

Keywords: extraocular muscle, swept source anterior segment optical coherence tomography and strabismus re-operation

\section{Introduction}

In strabismic eyes, re-operation is often not intended but it appears as a special concern. The rate of re-operation varies but it is likely to be less than $10 \%{ }^{1}$ In routine clinics, when we encounter patients with residual or over corrected ocular deviation, we undertake a detailed investigation including previous surgical details, amount of residual deviation, extra ocular movements, and the evidence of conjunctival scarring along operated muscles. With this knowledge, we operate in the same eye or the other eye depending upon the status of un-operated muscles and other practical factors. When surgical details are lost or when they are not kept on record, then the surgical planning becomes challenging. Again, with the basic knowledge of conjunctival scarring, muscle site and patients recalling abilities, we can plan a surgery, but, if we plan to operate on the same eye, then it becomes an exploratory surgery, and if we plan on the other eye then it becomes the subsequent 
plan (assuming optimal surgery has been done in the previous eye). But we have witnessed that we do face some major practical challenges and even encounter residual or over-corrected ocular deviations, where it becomes more challenging to operate on them. Hence, to circumvent all these challenges, if we can reliably get the information on type and approximate amount of surgery, then the whole scenario becomes more predictable and scientific.

In developed countries or in set-ups where documentation is well preserved, the previous treatment details can be easily reviewed. Whereas in developing countries or in clinical set-ups where documentation is poor, or due to multiple surgeon visits and patient factors, the details may not be easily accessible. In such scenarios, surgical planning can be really challenging as patients becomes more unstable and bothersome. This further adds up if a third or fourth surgery is planned. Hence, in a nutshell, to address all these issues, gaining the knowledge on muscle location and their probable type of surgery (recession/resection) can provide a major relief to to treating surgeon as well as to the patients.

To identify such muscular details computed tomography (CT), magnetic resonance imaging (MRI), ultrasonography and/or ultrasound bio microscopy (UBM) can be used. $^{2-6}$ However, due to their gross imaging nature (CT, $\mathrm{MRI})$ and due to their contact nature (UBM), the derived information can be less accurate. Furthermore, earlier models of OCT's can also be used, however, their limited penetration and narrow area of scanning again limit our desired information. Hence, to improve on these limitations, a swept source anterior segment optical coherence tomography (SS-ASOCT) study was undertaken to find its role in strabismus re-operation with lost previous surgical details. $^{7-9}$

\section{Methods}

\section{Patient Selection Criteria}

Patients with ocular misalignment presenting to our outpatient services at Dr Rajendra Prasad Centre for Ophthalmic Sciences, AIIMS, New Delhi, India, between February 2020 and March 15th 2021 were assessed. Individuals with significant ocular deviation (over or under correction) after previous surgery were segregated from naïve cases, and in this manner, a total of 30 patients were identified. Out of these 30 patients, a total of 20 patients were excluded because those patients had detailed reports on previous surgical interventions. In the remaining 10 cases, the previous surgical details were not available, and hence they were included in the present study.

The 10 patients underwent a detailed orthoptic work up, and then depending upon the amount of ocular deviation and patients' preference, the re-operation plans were proposed. In the absence of surgical details, we routinely do aslit lamp bio-microscopy based examination and operate based on those details (as stated in the introduction section). Here, in 10 subjects, we additionally included the SS-ASOCT (Tomey Corp, Nagoya, Japan) based evaluation. On OCT, the muscle insertion sites were screened in detail to look for their presence or absence, and their morphology in presence (distance from the angle and the possible recession or resection nature). The ethical clearance for the present exercise was obtained from the institution's ethical committee (All India Institute of Medical Sciences, New Delhi. India) in early 2020, and the study strictly adhered to the Declaration of Helsinki. In all patients, prior to imaging, a written informed consent was obtained, and all 10 eyes of 10 patients were screened by a single author (AP) but the surgeries were performed by four different authors (AP, PS, SP and RS).

\section{Examination Protocol}

In all ten patients both eyes were scanned. Prior to scanning, each patient was informed about the testing procedure, and then they were asked to sit in front of the machine and requested to position their chin, on the chin rest. After entering patient details, a pre-operative cataract scanning mode was selected (this is because the global and the angle scan modes were not able to measure the desired distances along the ocular surface). The test was begun by positioning the cross lines (plus lines) along the exposed sclera, that is lateral sclera during adduction, medial sclera during abduction, inferior sclera during elevation, and superior sclera during depression. With this, the continuous scan delineated a cross-sectional scleral detail from angle to forniceal area in one frame, including muscle details (more than $15 \mathrm{~mm}$ total scan width).

To scan the medial rectus muscle, the eye is positioned in abduction, and the horizontal scan line is positioned along the supero-medial sclera, then the joystick is gradually moved downwards till the infero-medial sclera is screened (Supplementary Video S1). This pattern of scanning has not been proposed previously, but we learnt this from our current observations, and we propose this for future examinations. This is because the muscle possesses 
a definite width which usually varies up to 10 millimeters, hence a single point or a single line-based examination is going to be erroneous if we do not consider this. It also aids the advantage of detailed muscle screening in the presence of a scarred ocular surface. Hence, by following a vertical scanning protocol for a horizontal rectus and a horizontal scanning for a vertical rectus the chances of muscle identification are better. Again, the vertical scanning for lateral rectus was initiated from supero-temporal sclera till the infero-temporal sclera, and the horizontal scanning for vertical recti were initiated from superotemporal sclera to supero-nasal sclera for superior recti, and from infero-temporal sclera to infero-nasal sclera for inferior recti, respectively (Supplementary Video S2).

In all 10 eyes the required muscle positions were identified optimally, and required measurements were taken using an inbuilt straight caliper from angle to consistently visible muscle point. Subsequently, based on these ASOCT findings, the surgical planning in all eyes were modified and based on this, either a surgical exploration or an augmentation surgery was planned. Intra-operatively confirmatory measurements were taken from outer limbus to muscle insertion (using a Castroviejo caliper).

\section{Statistical Analysis}

The mean pre- and post-operative deviations, ASOCT and intraoperative measurements were statistically compared. Data was entered in an excel sheet and statistical analysis was performed using Stata software 12.1. Paired $t$ test was applied to assess the significance between two mean differences, and a $p$ value of $<0.05$ was considered statistically significant.

\section{Results}

\section{Demographics}

The mean age of the 10 patients was $23.7 \pm 5.75$ years. Out of these 10 patients, seven were male and three were female. Seven patients had bilateral surgery, two patients had right eye surgery, and one patient had left eye surgery. Six patients had residual exotropia, two patients had consecutive exotropia, one patient had residual infantile esotropia and the remaining one patient had over corrected monocular elevation deficit. Two patients $(20 \%)$ underwent surgery three times before, five patients $(50 \%)$ underwent it twice, and three patients $(30 \%)$ underwent surgery only once.

\section{SS-ASOCT versus Intraoperative Correlation}

The mean SS-ASOCT derived measurement was 8.90 $\pm 1.85 \mathrm{~mm}$ ( $\min 7.2 \mathrm{~mm}$, median $8.3 \mathrm{~mm}$, and $\max$ $12.7 \mathrm{~mm}$ ), and the mean intraoperative measurement was $9.12 \pm 2.14 \mathrm{~mm}$ (min $7 \mathrm{~mm}$, median $8 \mathrm{~mm}$, and $\max$ $13.5 \mathrm{~mm}$ ). A difference of $0.21 \pm 1.31 \mathrm{~mm}$ was noted between the two methods, and on paired $t$ test the difference was statistically not significant $(\mathrm{p}=0.57)$. The mean preoperative deviation was $27.3 \pm 12.46$ prisms which went down to -1.8 \pm 8.08 prisms with surgery (the minus sign indicates under correction or less than orthophoria). Hence a net correction of around 25 prisms was achieved. (The details of type and amount of surgery has been enumerated in Table 1).

\section{Identification of Normal Muscle}

In normal or un-operated eyes, the muscle begins as a thin, curved, hypoechoic area at a fixed distance from the angle (Figure 1). This corresponds to initial tendinous portion of a muscle, then, when tracing is continued posteriorly, the corresponding hypoechoic area assumes a progressively larger space, which then corresponds to muscle belly (Figure 2). It is difficult to decipher at what point the muscle began its transition from tendon to belly, but certainly we can identify the muscle in almost all normal subjects. During these tracings, the ocular coat on the outer side as well as on the inner side had a regular convex contour (Figures 3 and 4). And the overall thickness fairly remained uniform with no significant irregularities.

\section{Initial Features in an Operated Eye}

In operated eyes, firstly, the initial ocular coat from angle to muscle insertion remained fairly regular (this we will term as the anterior ocular coat from now on as it is anterior to muscle insertion) (Figure 5). Whereas, beyond the original muscle insertion, the ocular coat showed a definite loss in its thickness and contour (this we will term as the posterior ocular coat from now on). These posterior changes became more pronounced as we approach towards the fornices (Figure 5).

\section{Identification of a Recessed or Resected Medial Rectus Muscle}

In recessed medial rectus muscle eyes, the anterior ocular coat contour remained fairly unremarkable, whereas the posterior ocular coat contour had variable thinning in absence of muscle specific identities. This was usually 


\begin{tabular}{|c|c|c|c|c|c|}
\hline & 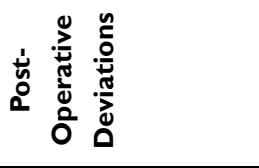 & 高 & $\begin{array}{l}\stackrel{0}{\infty} \\
\stackrel{\infty}{\forall}\end{array}$ & $\overline{\underline{g}}$ & 商 \\
\hline & 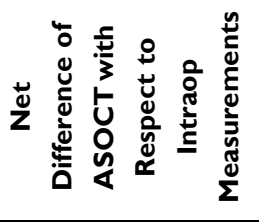 & 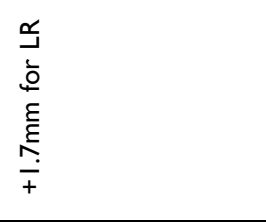 & 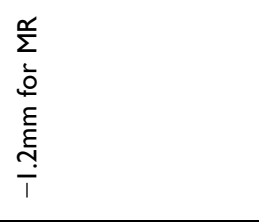 & 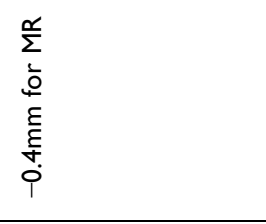 & 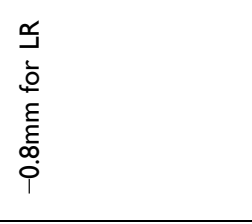 \\
\hline & 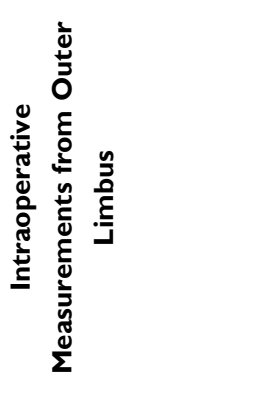 & 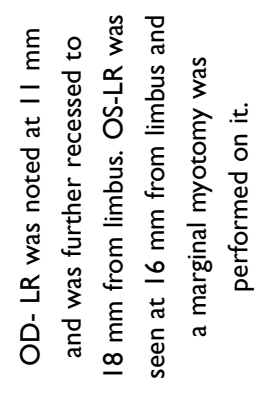 & 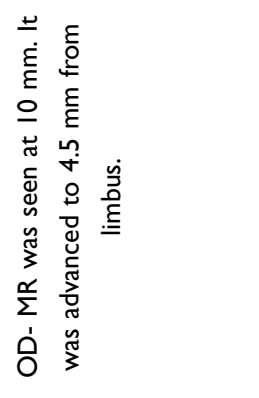 & 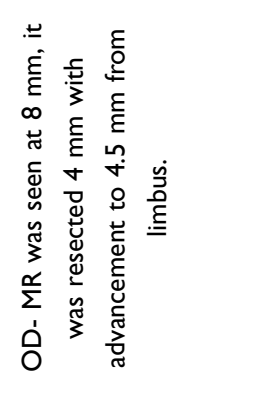 & 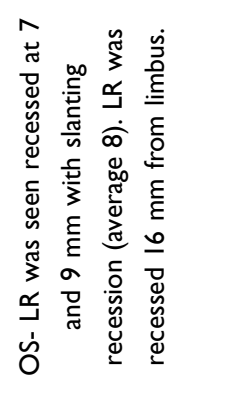 \\
\hline & 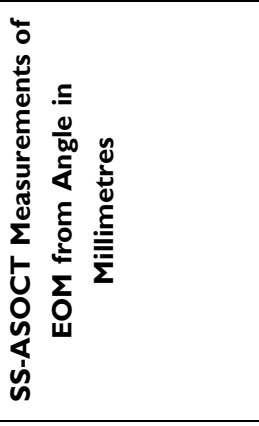 & 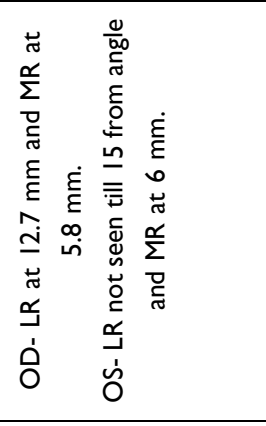 & 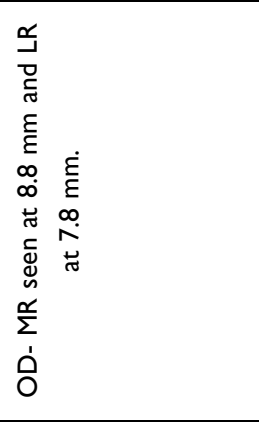 & 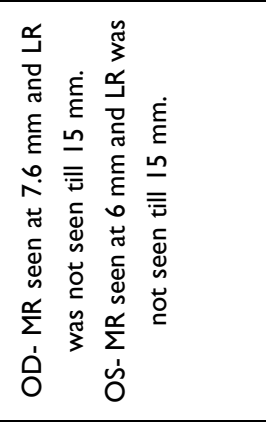 & 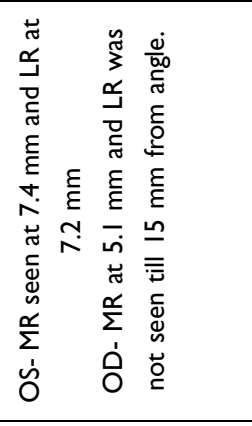 \\
\hline & 尊 & 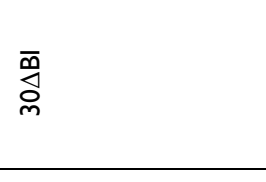 & 离 & 嵒 & $\begin{array}{l}\bar{m} \\
\text { ờ }\end{array}$ \\
\hline & 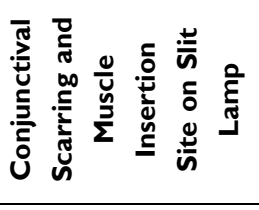 & 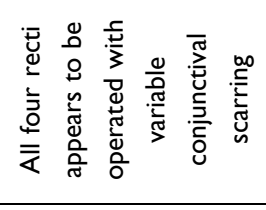 & 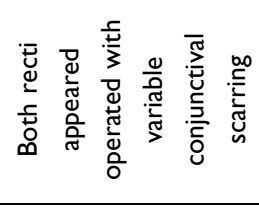 & 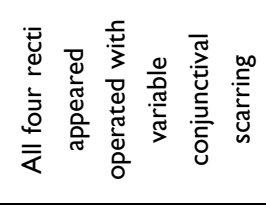 & 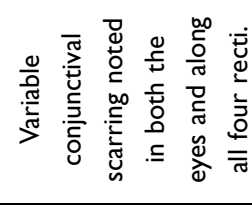 \\
\hline & 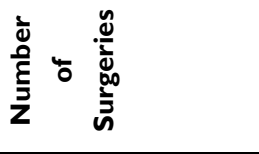 & $\stackrel{0}{\xi}$ & $\stackrel{0}{\xi}$ & $\stackrel{\varrho}{\underline{\xi}}$ & $\stackrel{0}{0}$ \\
\hline & 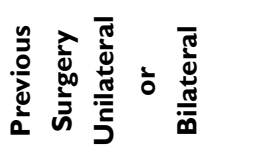 & ว & Оे & จ & จ \\
\hline & 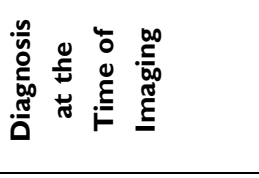 & 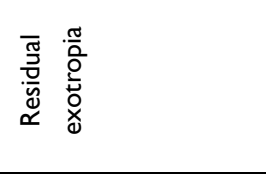 & 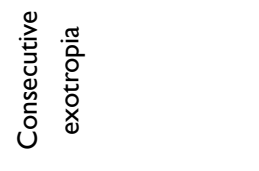 & 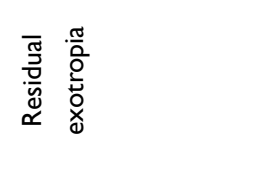 & 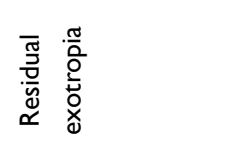 \\
\hline & 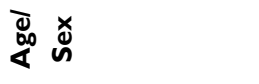 & ડ্ণ $\Sigma$ & त्र $\Sigma$ & 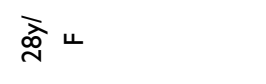 & స్ల $\Sigma$ \\
\hline & $\bar{n} \mathbf{z}$ & - & $N$ & $m$ & $\nabla$ \\
\hline
\end{tabular}




\begin{tabular}{|c|c|c|c|c|}
\hline 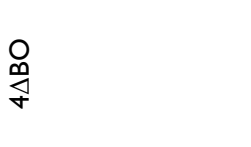 & 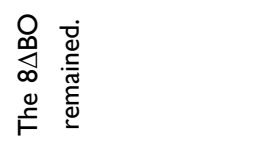 & 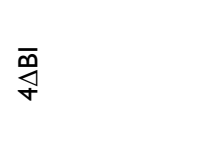 & 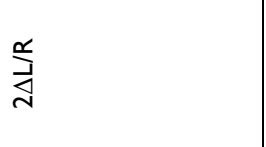 & $\stackrel{\bar{g}}{\vec{f}}$ \\
\hline 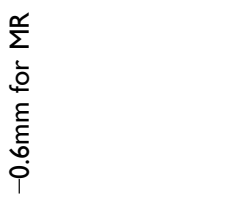 & 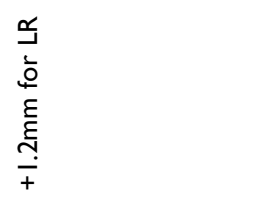 & 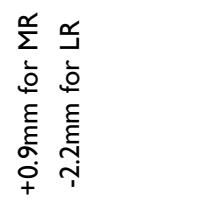 & 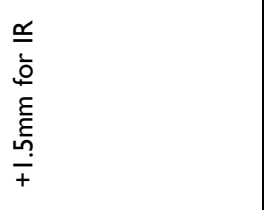 & 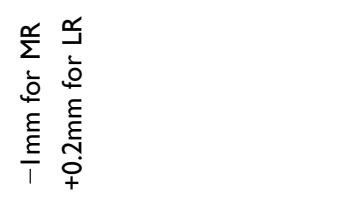 \\
\hline 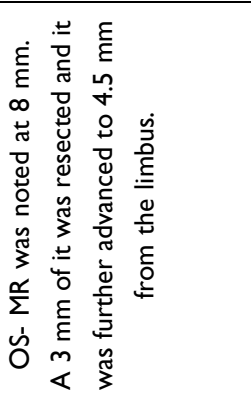 & 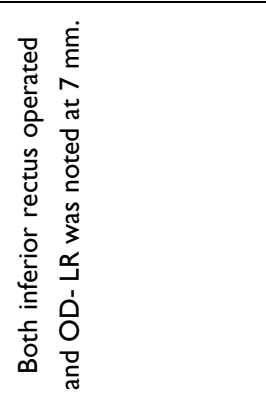 & 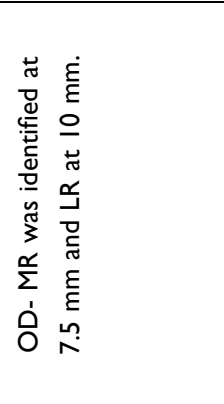 & 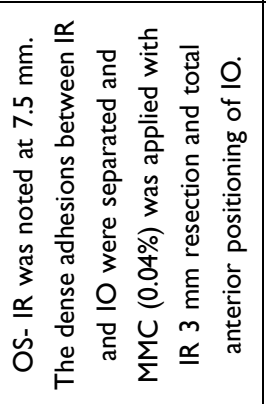 & 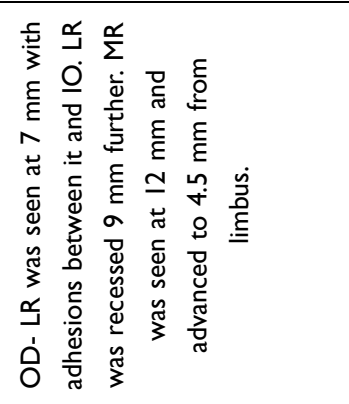 \\
\hline 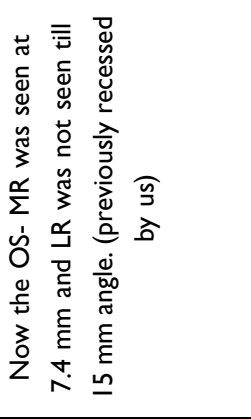 & 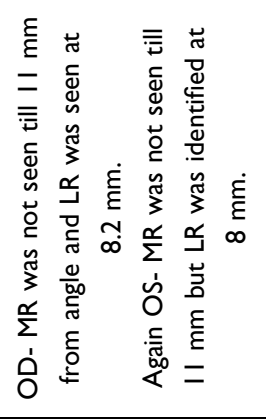 & 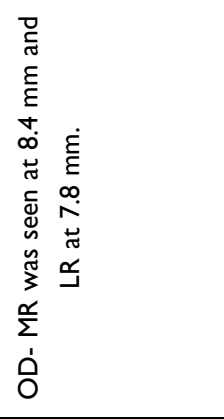 & 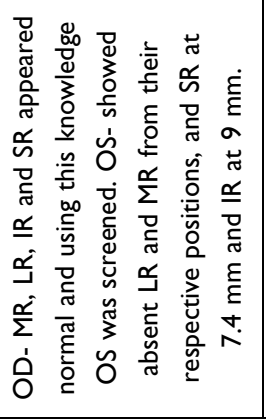 & 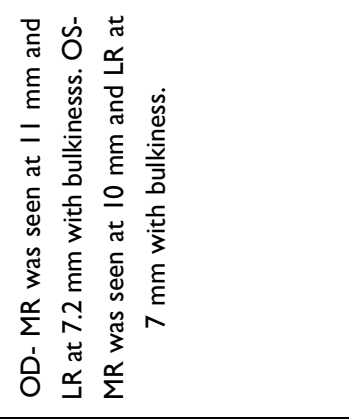 \\
\hline হ্ণ & 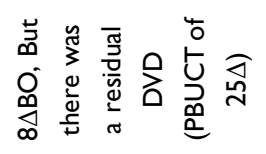 & 峛 & 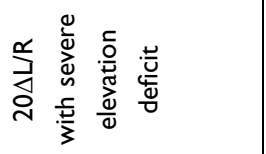 & 獣 \\
\hline 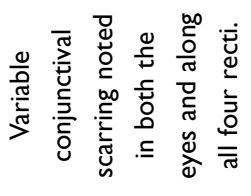 & 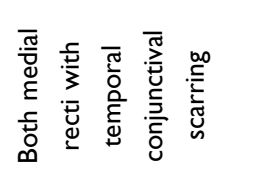 & 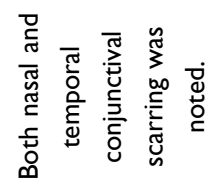 & 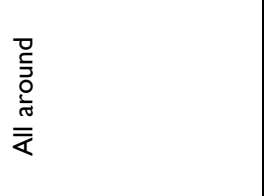 & 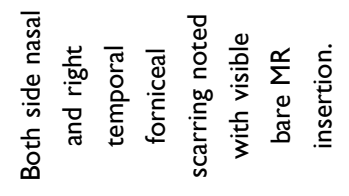 \\
\hline$\stackrel{\jmath}{\xi}$ & 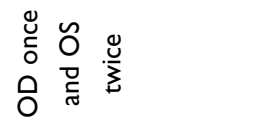 & $\begin{array}{l}\stackrel{\Xi}{E} \\
\stackrel{F}{F}\end{array}$ & $\begin{array}{l}\underset{\mathscr{J}}{E} \\
\stackrel{F}{F}\end{array}$ & $\stackrel{\varrho}{\tilde{\Xi}}$ \\
\hline ว & ว & ว & Ø̃ & $\supset$ \\
\hline 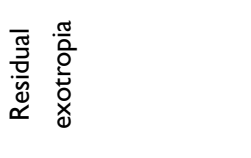 & 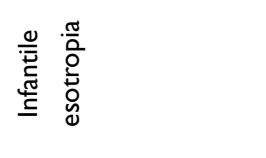 & 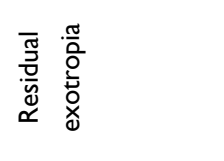 & 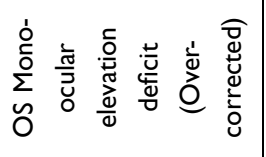 & 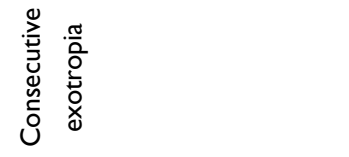 \\
\hline ఫ्रे $\Sigma$ & ৯ & $\underset{\sim}{\overline{\widehat{े}}} \Sigma$ & $\underline{\widehat{\widehat{D}}}$ ᄂ & 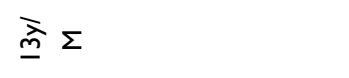 \\
\hline in & 0 & $\wedge$ & $\infty$ & $a$ \\
\hline
\end{tabular}




\begin{tabular}{|c|c|}
\hline 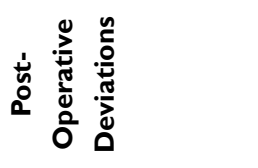 & $\begin{array}{l}0 \\
\text { यิ } \\
\end{array}$ \\
\hline 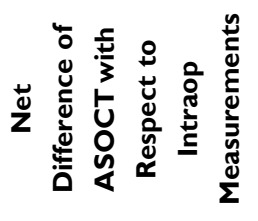 & 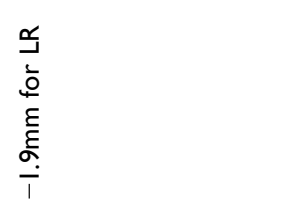 \\
\hline 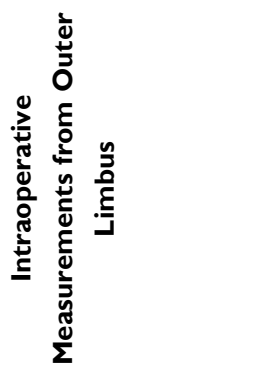 & 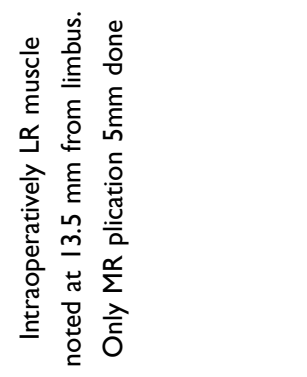 \\
\hline 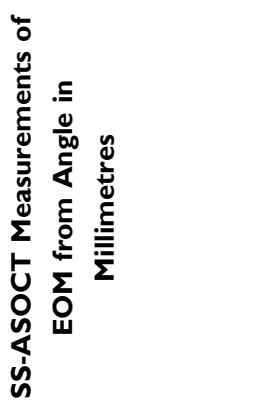 & 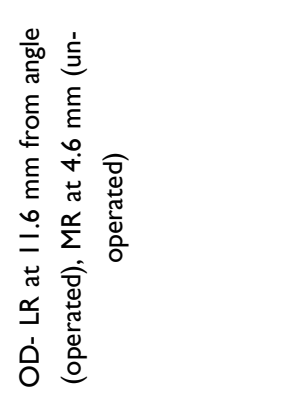 \\
\hline d & 啇 \\
\hline 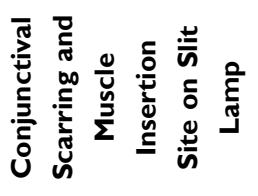 & 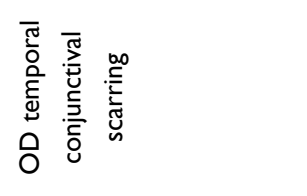 \\
\hline 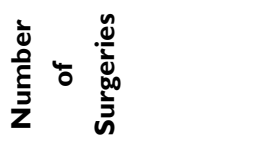 & 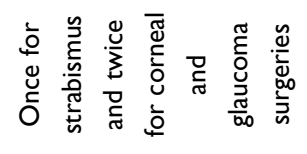 \\
\hline 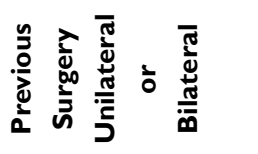 & О \\
\hline 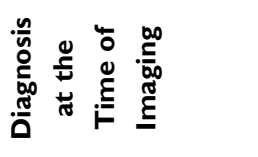 & 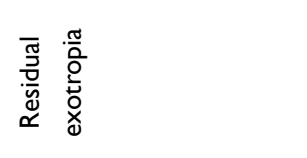 \\
\hline 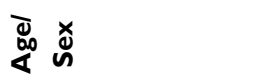 & $\overline{\bar{\lambda}} \Sigma$ \\
\hline $\bar{n} \stackrel{0}{z}$ & 으 \\
\hline
\end{tabular}

observed till 10 to $11 \mathrm{~mm}$ from the angle and beyond that a prominent shadow due to plica semilunaris and the caruncle often hindered the visibility on several occasions.

Figure 5 shows an example, where the anterior ocular coat is of normal contour, but the posterior ocular coat is having a disturbed contour with absent muscle marks till 10 to $11 \mathrm{~mm}$. This prominent hypoechoic area just anterior to overlying shadow hints at it being a recessed muscle, and intra operative measurements confirmed the SSASOCT features of recessed medial rectus muscle with dense fibrosis.

In a resected medial rectus muscle, the anterior ocular coat again showed a regular contour. Whereas from insertion point onwards, the posterior coat was thicker and irregular with variable conjunctival folds. Furthermore, the muscle specific identities were witnessed at this point only (Figure 6). Here the muscle appears thicker due to the presence of muscle belly at the original insertion site, and in this eye, also, the intraoperative observations confirmed a resected muscle with minimally stretched scar.

\section{Identification of a Recessed or Resected Lateral Rectus Muscle}

In contrast to the medial rectus muscle, the imaging and characterization of lateral rectus muscle was easy. The wider working space, absence of caruncle and major conjunctival folds aided the scanning till 15 millimeters from angle.

In a recessed lateral rectus muscle, again the anterior ocular coat contour was unremarkable, whereas beyond a normal insertion point, the posterior ocular coat assumed a more dramatic form. Here, the posterior ocular coat was thin, irregular, and undulating in the absence of any muscle specific identities. In a small amount of recessions, in addition to the above features, a normal caliber muscle was identified at or within 12 millimeters from the angle. And in a large amount of recessions, the muscle specific identities were not witnessed till 15 millimeters or beyond from the angle (indicative of 9 millimeters or more recession) (Figure 7). Therefore, under normal anterior ocular coat and a significantly disturbed posterior ocular coat with absent muscle specific identities were suggestive of a recessed lateral rectus muscle (Figure 7).

Similarly, in eyes with resected lateral rectus muscle, a bulky rectus muscle (variably) at the insertion with minimally disturbed ocular coat contours were noted. Again here, the stretched scar influenced the muscle position (Figure 8). In some unusual circumstances, the 

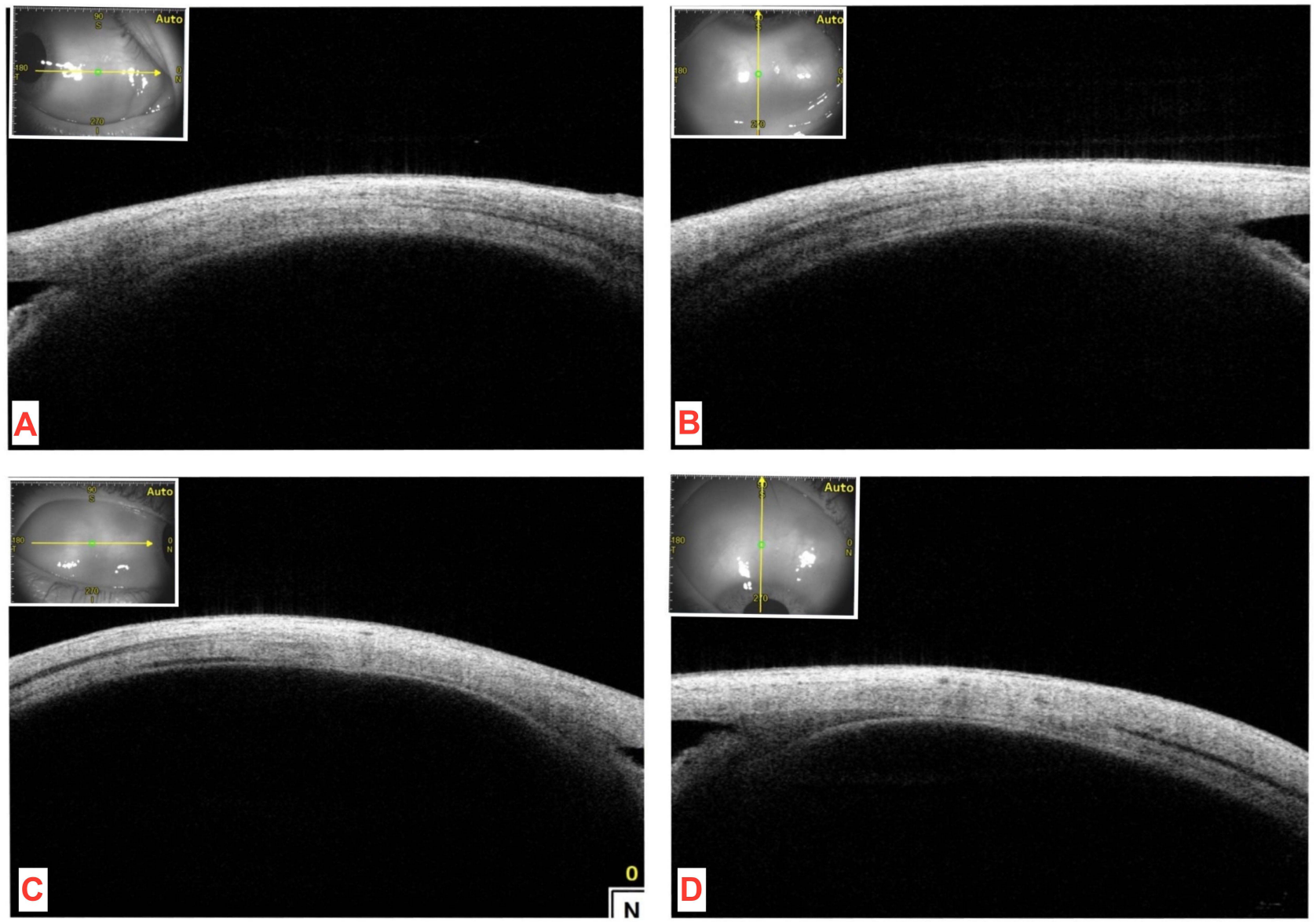

Figure I Normal extra ocular muscle insertions on SS-ASOCT. The medial (A), inferior (B), lateral (C) and superior rectus (D) muscles can be localized clearly along different distances on sclera.

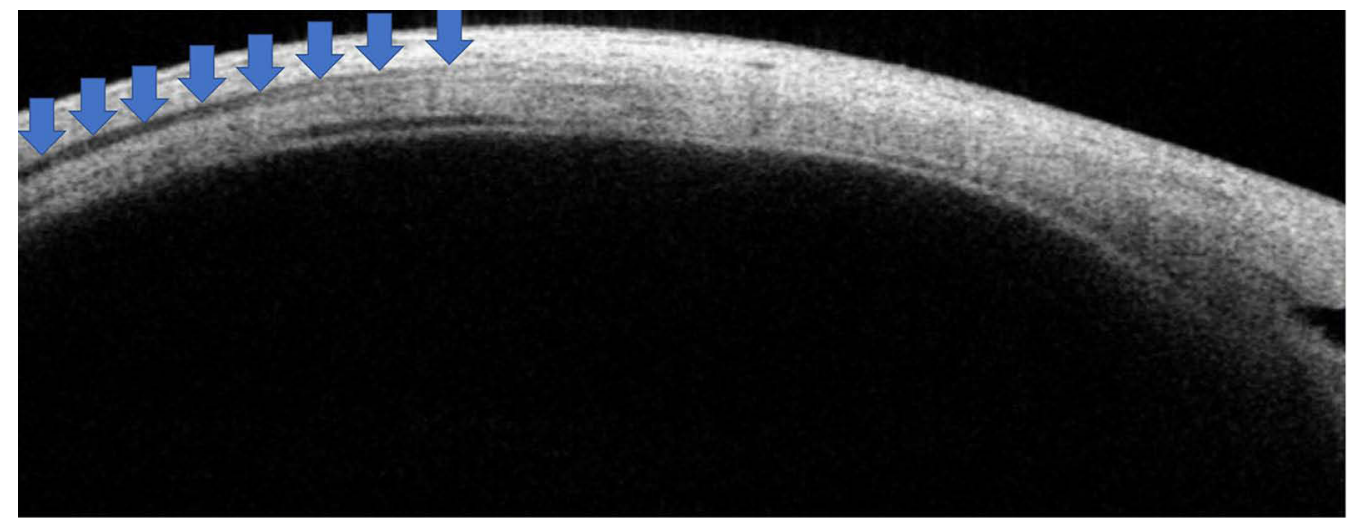

Figure 2 The muscles begin as a very faint hypoechoic area (corresponding with tendon) (anterior blue arrows) and then gradually appears as a well-defined hypoechoic area corresponding to the belly (posterior blue arrows).

resected lateral rectus muscle bulk was disproportionately thicker in the absence of any confounders. And while looking for such causes, intra operatively we noted the abnormal adhesions between the lateral rectus muscle and the inferior oblique muscle (dragging of inferior oblique anteriorly) and hence the appearance. 


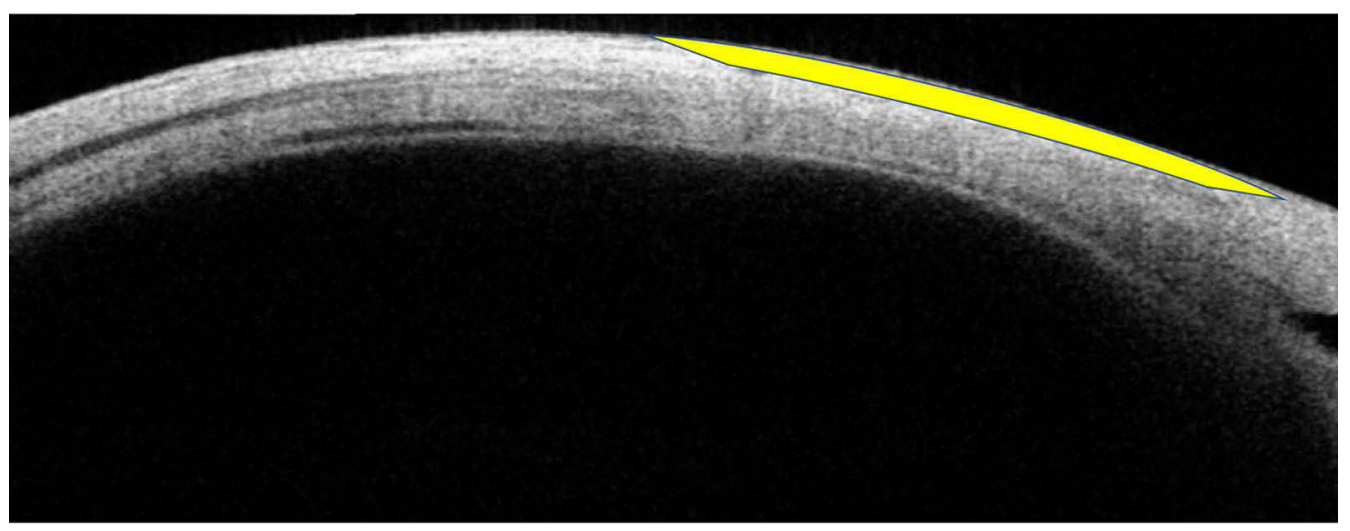

Figure 3 Well defined anterior ocular coat contour (yellow arc).

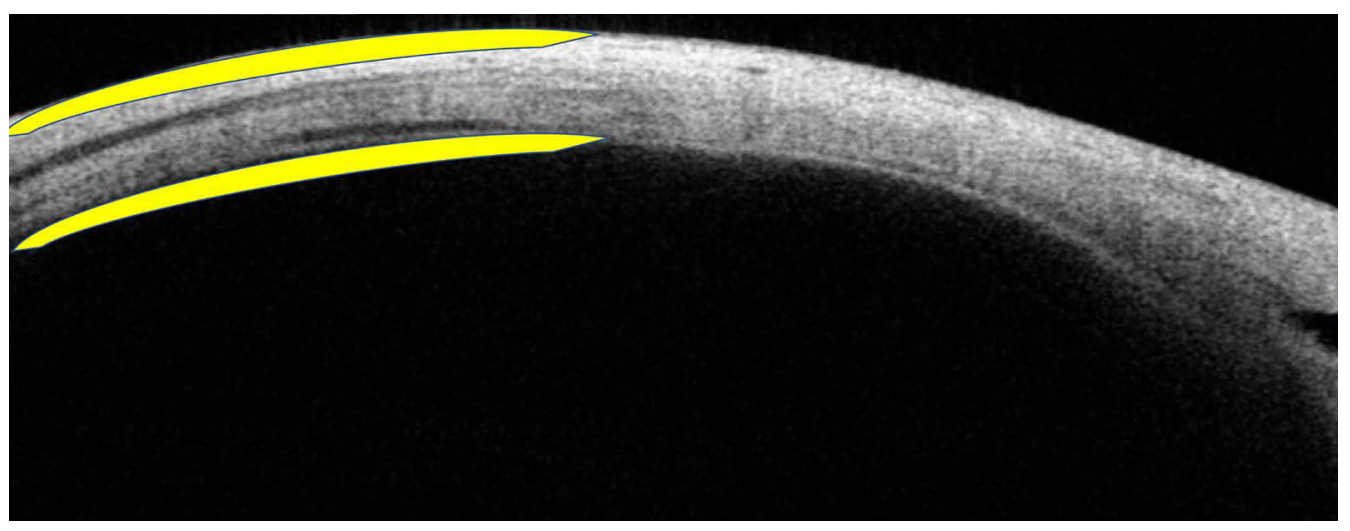

Figure 4 Well defined posterior ocular coat contours (outer and inner, yellow arcs).

\section{Discussions}

The existing literature of anterior segment optical coherence tomography (ASOCT) for extra ocular muscle imaging supports the claim that we can reasonably identify the anatomical location of any recti muscle. ${ }^{7-11}$ This study adds a more important role for ASOCT in strabismus where in operated eyes we can use it as a scavenging tool for surgical planning.

Overall, we noted a small difference between the two measurement methods (less than $1 \mathrm{~mm}$ ) that is intraoperative measurements and the ASOCT, this emphasizes that we can obtain very close muscle location readings using ASOCT without any invasion, provided we examine carefully. In our observation, the one-to-one comparison as shown in Table 1 also supported this view, where individual case-based comparisons were also accurate, reliable, and useful. During this study, the ASOCT underestimated the muscle position up to 2.2 millimeters, and it overestimated up to 1.7 millimeters (with respect to intraoperative readings) depending upon the case scenario. This seems acceptable because we do get variations of up to 2 millimeters in normal eye studies on ASOCT as well.

These variations can be attributed to individual variations in normal muscle attachments and/or due to differences in assigned landmarks during surgical and ASOCT measurements. Considering these possibilities, we need to question the clear clinical benefit of considering this imaging in operated eyes. In our experience, the clinical benefits were genuinely remarkable, because when a patient seeks re-surgery, we used to plan and operate just based on preliminary evidence and assumptions without actually knowing where exactly the muscles are. In these scenarios, the imaging definitely added new knowledge which made our approaches scientifically better. Hence, imaging clearly benefitted over non-performance.

During ASOCT measurements there were some cautions which we took into consideration all the time and we recommend in future studies as well. 1) The 


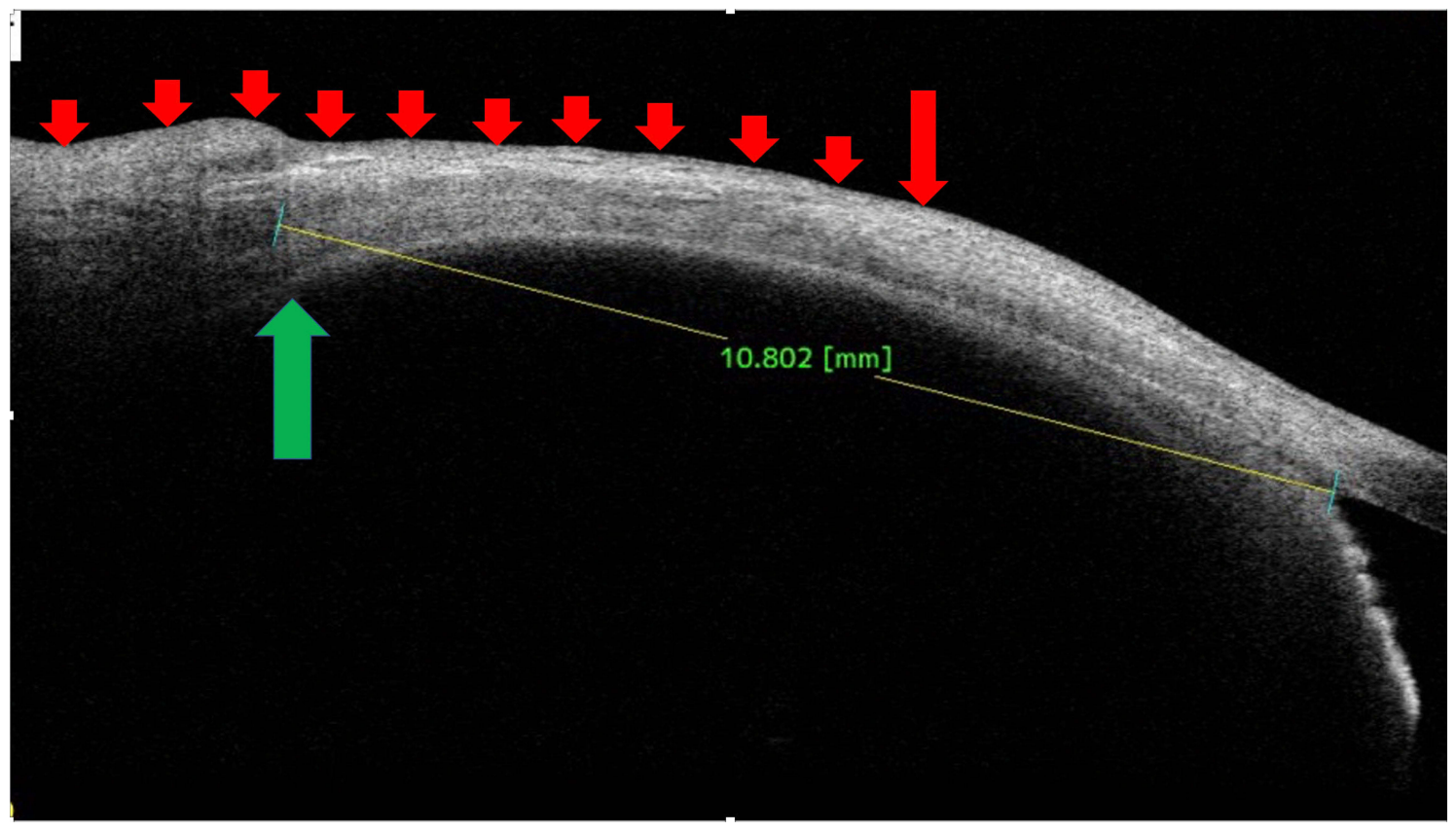

Figure 5 In a recessed medial rectus muscle, the anterior ocular coat contour appears to be normal, whereas from original insertion onwards (long red arrow) the posterior ocular coat looks variably thinned (smaller red arrows). The muscle corresponding hypoechoic area can be seen at $10.8 \mathrm{~mm}$. Hence, in the presence of disturbed posterior coat contour and distally situated muscle specifications, a recessed muscle is evident (green arrow). The later elevations along outer ocular coats were due to the conjunctival fold and/or the plica semilunaris (later small arrows).

orientation of the head needs a clear assertion, ${ }^{11}$ during our entire study period, we made sure that the straightahead gaze was maintained, and if any fallacies were noted then they were addressed immediately. 2) A single observer or surgeon observations were encouraged to maintain the uniformity. 3) A broader area of scleral search after detailed history and slit lamp examinations were encouraged to maximize the clinical benefits. 4) The axial length was taken into consideration at all times. ${ }^{12}$

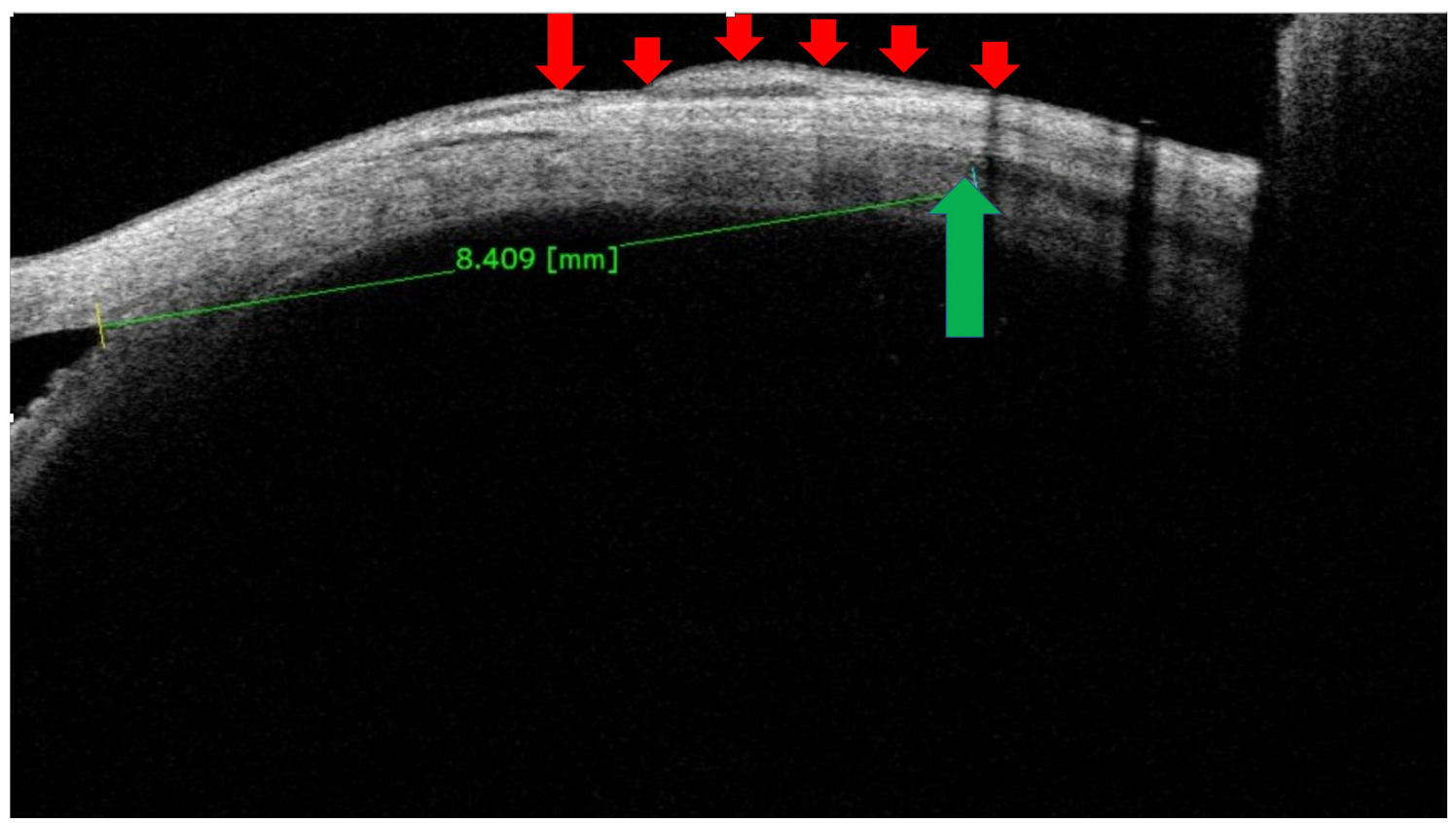

Figure 6 A resected medial rectus muscle, the muscle specific hypoechoic area is present at $8.4 \mathrm{~mm}$ (green arrow). Again, the anterior ocular coat prior to original insertion is regular (left to large red arrow), whereas the posterior ocular coat shows a variable thickness with conjunctival scarring (small red arrows). 


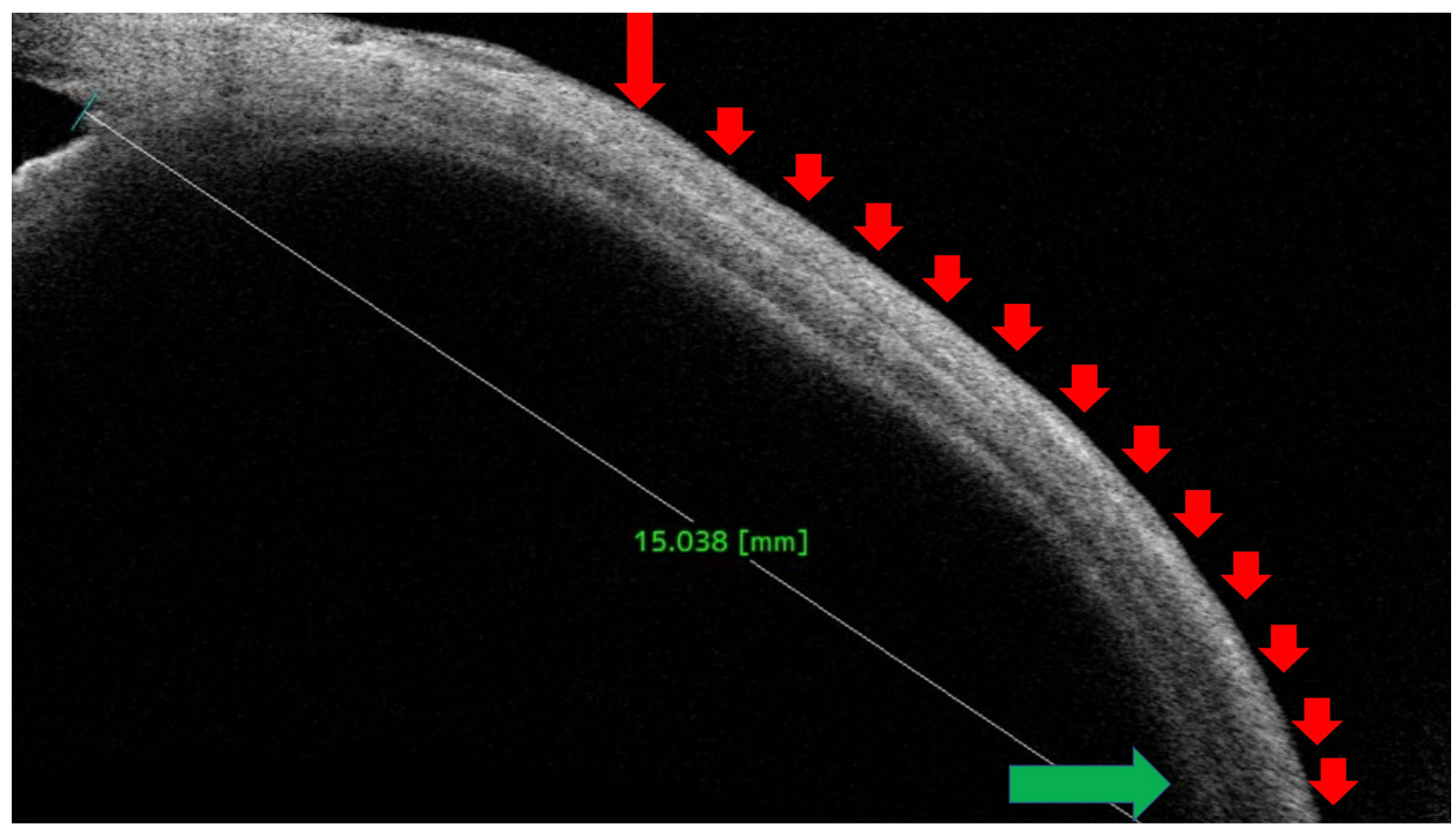

Figure 7 A recessed lateral rectus muscle. The anterior ocular coat is reasonably well maintained (left to large red arrow), whereas original insertion onwards the posterior ocular coat shows a significantly disturbed contour (multiple small arrows). The muscle specific hypoechoic area is not seen till 15 mm from the angle (green arrow), suggestive of a large amount of recessions (9 to $10 \mathrm{~mm}$ ).

Nevertheless, we feel that futuristic concepts such as shape analysis of extra ocular muscle can benefit our understandings immensely in identifying operated muscle details as compared to current cross-sectional imaging techniques. $^{13}$

\section{Strength of Our Study}

1. This novel observation explored the practical role of non-contact imaging (SS-ASOCT) in surgical planning's of re-operated eyes with lost surgical details.

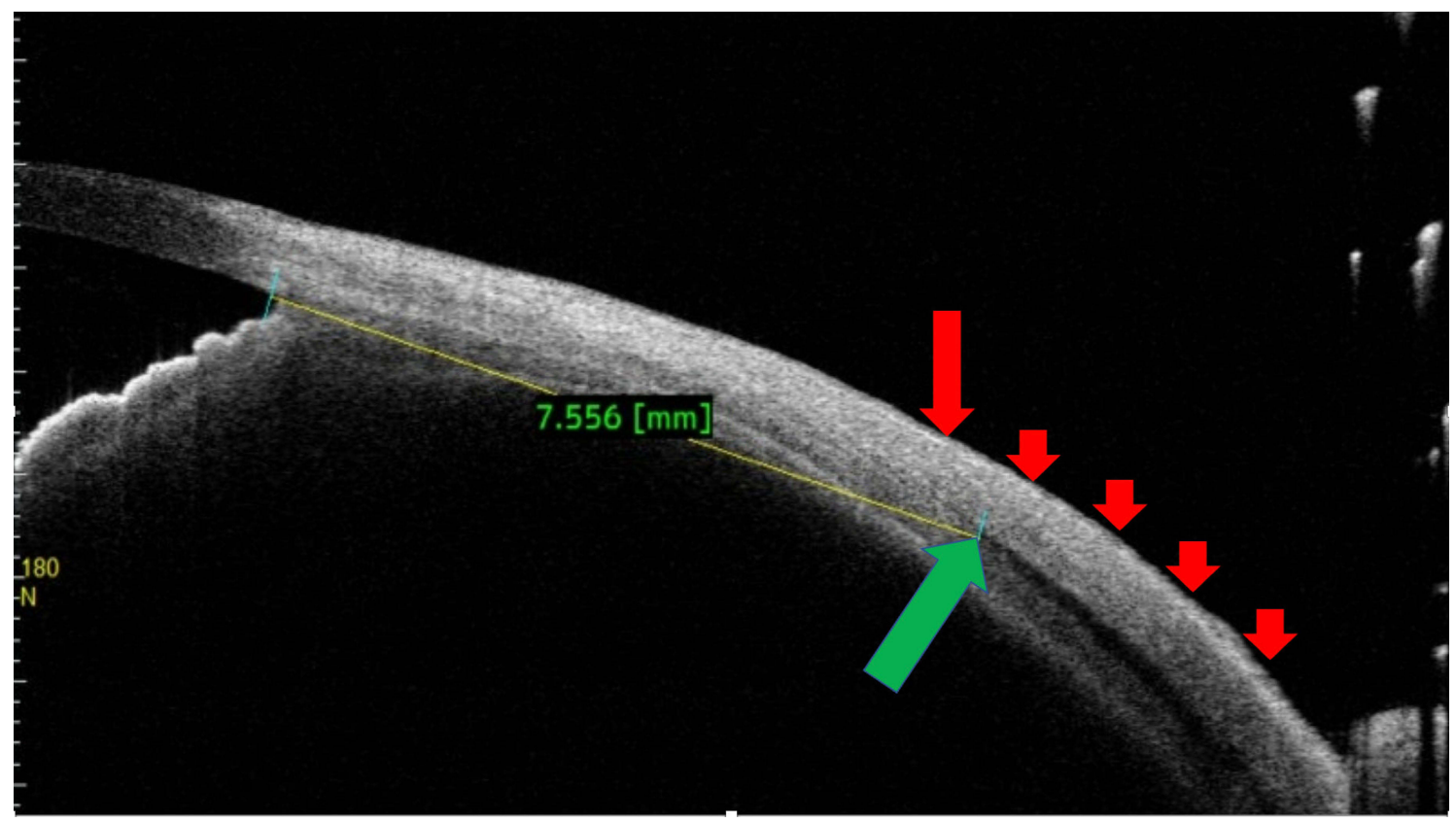

Figure $8 \mathrm{~A}$ resected lateral rectus muscle. The anterior ocular coat again remained reasonably intact but the original insertion onwards (large red arrow) the posterior ocular coat showed a variably disturbed morphology (multiple small red arrows). The muscle specific hypoechoic area can be seen at 7.5 mm from angle (green arrow). 
2. Through this study, the features of recessed and the resected muscle were highlighted. And intraoperatively, such notions helped in achieving greater clarity while handling the muscles.

3. The unique features of SS-ASOCT including wide angle imaging, faster scanning, and deeper penetration addressed our long-standing desire to locally investigate the muscle in strabismic eyes.

\section{Limitations of Our Study}

1. The current study had a relatively small sample size (this is because the great majority of patients had clear details of previous surgery as evidenced in our exclusion criteria).

2. In routine practices, as well as during this study, the universal landmarks were lacking. That is the outer limbus, and the angle markings may be having some discrepancy while measuring the distances.

3. The SS-ASOCT lacked the curved scale to measure the actual distances along scleral surface, and this may have posed some unseen errors in our measurements.

\section{Conclusions}

To conclude, while re-operating for residual strabismus with lost surgical details, the non-contact and quick SS-ASOCT can be used to predict the muscle locations and their nature of surgery. Additionally, intraoperative difficulties can be minimized by combining routine clinical skills with clinical imaging. Hence, in strabismus re-operations ASOCT seems to be a viable option in achieving desired goals.

\section{Funding}

There is no funding to report.

\section{Disclosure}

The authors report no conflicts of interest for this work.

\section{References}

1. Leffler CT, Vaziri K, Schwartz SG, et al. Rates of reoperation and abnormal binocularity following strabismus surgery in children. $\mathrm{Am}$ J Ophthalmol. 2016;162:159-166.e9. doi:10.1016/j.ajo.2015.10.022

2. Ozgen A, Ariyurek M. Normative measurements of orbital structures using CT. AJR Am J Roentgenol. 1998;170:1093-1096. doi:10.2214/ ajr.170.4.9530066

3. Demer JL, Kerman BM. Comparison of standardized echography with magnetic resonance imaging to measure extraocular musclesize. Am J Ophthalmol. 1994;118:351-361. doi:10.1016/ S0002-9394(14)72960-5

4. Tamburrelli C, Salgarello T, Vaiano AS, Scullica L, Palombi M, Bagolini B. Ultrasound of the horizontal rectus muscle insertion sites: implications in preoperative assessment of strabismus. Invest Ophthalmol Vis Sci. 2003;44(2):618-622. doi:10.1167/iovs.02-0112

5. Dai S, Kraft SP, Smith DR, Buncic JR. Ultrasound biomicroscopy in strabismus reoperations. $J$ AAPOS. 2006;10(3):202-205. doi:10.1016/j.jaapos.2006.01.209

6. Thakur N, Singh R, Kaur S, Kumar A, Phuljhele S, Sukhija J. Ultrasound biomicroscopy in strabismus surgery: efficacy in postoperative assessment of horizontal muscle insertions. Strabismus. 2015;23(2):73-79. doi:10.3109/09273972.2015.1025987

7. Liu X, Wang F, Xiao Y, Ye X, Hou L. Measurement of the limbus insertion distance in adult strabismus patients with anterior segment optical coherence tomography. Invest Ophthalmol Vis Sci. 2011;52:8370-8373. doi:10.1167/iovs.11-7752

8. Ngo CS, Smith D, Kraft SP. The accuracy of anterior segment optical coherence tomography (AS-OCT) in localizing extraocular rectus muscles insertions. J AAPOS. 2015;19(3):233-236. doi:10.1016/j. jaapos.2015.03.012

9. Pujari A, Agarwal D, Sharma N. Clinical role of swept source optical coherence tomography in anterior segment diseases: a review. Semin Ophthalmol. 2021;1-8. doi:10.1080/ 08820538.2021.1897854

10. Pihlblad MS, Erenler F, Sharma A, Manchandia A, Reynolds JD. Anterior segment optical coherence tomography of the horizontal and vertical extraocular muscles with measurement of the insertion to limbus distance. $J$ Pediatr Ophthalmol Strabismus. 2016;53 (3):141-145. doi:10.3928/01913913-20160405-05

11. Park KA, Lee JY, Oh SY. Reproducibility of horizontal extraocular muscle insertion distance in anterior segment optical coherence tomography and the effect of head position. $J$ AAPOS. 2014;18(1):15-20. doi:10.1016/j.jaapos.2013.11.005

12. El-Fayoumi D, Bahgat N, Khafagy M, et al. Horizontal extraocular muscle insertion site in relation to axial length using swept-source anterior segment OCT. Clin Ophthalmol. 2020;14:3583-3589. doi:10.2147/OPTH.S262916

13. Shibata K, Fujiwara A, Hamasaki I, et al. Shape analysis of rectus extraocular muscles with age and axial length using anterior segment optical coherence tomography. PLoS One. 2020;15(12):e0243382. doi:10.1371/journal.pone. 0243382
Clinical Ophthalmology

\section{Publish your work in this journal}

Clinical Ophthalmology is an international, peer-reviewed journal covering all subspecialties within ophthalmology. Key topics include: Optometry; Visual science; Pharmacology and drug therapy in eye diseases; Basic Sciences; Primary and Secondary eye care; Patient Safety and Quality of Care Improvements. This journal is indexed on PubMed
Central and CAS, and is the official journal of The Society of Clinical Ophthalmology (SCO). The manuscript management system is completely online and includes a very quick and fair peer-review system, which is all easy to use. Visit http://www.dovepress.com/ testimonials.php to read real quotes from published authors. 